\title{
Intravenous Immunoglobulin may Reverse Multisystem Inflammation in COVID-19 Pneumonitis and Guillain-Barré Syndrome
}

\author{
Nilanchal Chakraborty ${ }^{1}$, Hrishikesh Kumar ${ }^{2}$
}

\begin{abstract}
Introduction: The novel coronavirus disease 2019 (COVID-19) poses an unprecedented crisis for public health, although several potential therapies have been provisionally applied but a unified consensus is yet to be achieved.

Case description: A 75-year-old man, COVID-19 reverse transcription-polymerase chain reaction (RT-PCR) positive on admission, presented with acute onset progressively ascending weakness of all four limbs. Nerve conduction velocity (NCV) study suggested acute demyelinating and axonal type of motor polyradiculoneuropathy. Hence, Guillain-Barré syndrome (GBS) related to COVID-19 infection was considered. His respiratory status worsened to severe acute respiratory distress syndrome (ARDS) on the second week of illness. He was started on intravenous immunoglobulin (IVlg) dosed over 5 days. His ventilator support started to improve after the 10th day of admission. His inflammatory markers started to improve, ventilator supports were weaned down and he was extubated on the 17th day of illness. Intravenous immunoglobulin is rich in viral immunoglobulin $\mathrm{G}(\mathrm{IgG})$, competitively binds Fcy receptor, preventing SARS-CoV-2 spike protein from attaching to the angiotensinconverting enzyme 2 (ACE 2) receptor, inhibiting viral entry into the cell.

Clinical significance: Intravenous immunoglobulin can inhibit the production of inflammatory factors and decrease inflammatory injury, multisystem inflammation (MSI) in SARS-CoV-2.

Conclusion: While the use of hyperimmune globulin requires a tedious job of collection from convalescent patients with verified and adequate titers, the use of IVlg could be an easier option to modulate the immune storm and faster recovery in SARS-CoV-2.

Keywords: Acute respiratory distress syndrome, Coronavirus disease 2019, Guillain-Barré syndrome, Intravenous immunoglobulin, Multisystem inflammation.

Indian Journal of Critical Care Medicine (2020): 10.5005/jp-journals-10071-23688
\end{abstract}

\section{BACKGROUND}

The novel coronavirus disease 2019 (COVID-19) poses an unprecedented crisis for public health. Several potential therapies, including supportive interventions, immunomodulatory agents, antiviral therapy, and transfusion of convalescent plasma, have been provisionally applied but a unified consensus is yet to be achieved. Considering the rapid and catastrophic spread of the pandemic, there is an urgent need to testify available therapeutic options while a continuous search for novel therapies is ongoing. Intravenous immunoglobulin (IVIg) derived from the plasma of thousands of healthy donors has been used in different primary and secondary immune deficiencies, autoimmune conditions, and neuroimmunological disorders. Recently, only a few case reports have suggested its use in COVID-19 induced Guillain-Barré Syndrome (GBS) and the first case was reported from Shanghai, China., ${ }^{1,2}$

\section{Case Description}

In our case, a 75-year-old man presented with a 1-day history of acute onset progressively ascending weakness of all four limbs. He had decreased deep tendon reflexes on presentation and breathing difficulty with a single breath count of 7 ; his weakness was the Medical Research Council (MRC) grade 2/5 in all four limbs on presentation. There was no history of fever or other viral prodromes at presentation. He was intubated and put on mechanical ventilation for respiratory support.
${ }^{1}$ Department of Anesthesiology and Critical Care Medicine, Institute of Neurosciences, Kolkata, West Bengal, India

${ }^{2}$ Department of Neurology, Institute of Neurosciences, Kolkata, West Bengal, India

Corresponding Author: Nilanchal Chakraborty, Department of Anesthesiology and Critical Care Medicine, Institute of Neurosciences, Kolkata, West Bengal, India, Phone: +91 9629392583, e-mail: nilanchal83@gmail.com

How to cite this article: Chakraborty N, Kumar H. Intravenous Immunoglobulin may Reverse Multisystem Inflammation in COVID-19 Pneumonitis and Guillain-Barré Syndrome. Indian J Crit Care Med 2020;24(12):1264-1268.

Source of support: Nil

Conflict of interest: None

Cerebrospinal fluid (CSF) analysis 2 days after presentation showed one lymphocyte with protein $39 \mathrm{mg} / \mathrm{dL}$. Nerve conduction velocity (NCV) (Figs 1 to 4) study revealed reduced compound muscle action potential (CMAP) amplitudes and conduction velocities of bilateral median and ulnar nerves. Bilateral tibial and peroneal nerves were inexcitable. Bilateral median, ulnar, tibial, and peroneal " $\mathrm{F}$ " responses were non-recordable. Acute demyelinating and axonal type of motor polyradiculoneuropathy related to COVID19 infection was considered. Cerebrospinal fluid picture can be a

() The Author(s). 2020 Open Access This article is distributed under the terms of the Creative Commons Attribution 4.0 International License (https://creativecommons. org/licenses/by-nc/4.0/), which permits unrestricted use, distribution, and non-commercial reproduction in any medium, provided you give appropriate credit to the original author(s) and the source, provide a link to the Creative Commons license, and indicate if changes were made. The Creative Commons Public Domain Dedication waiver (http://creativecommons.org/publicdomain/zero/1.0/) applies to the data made available in this article, unless otherwise stated. 
IVIg may Reverse Multisystem Inflammation in COVID-19 Pneumonitis and Guillain-Barré Syndrome

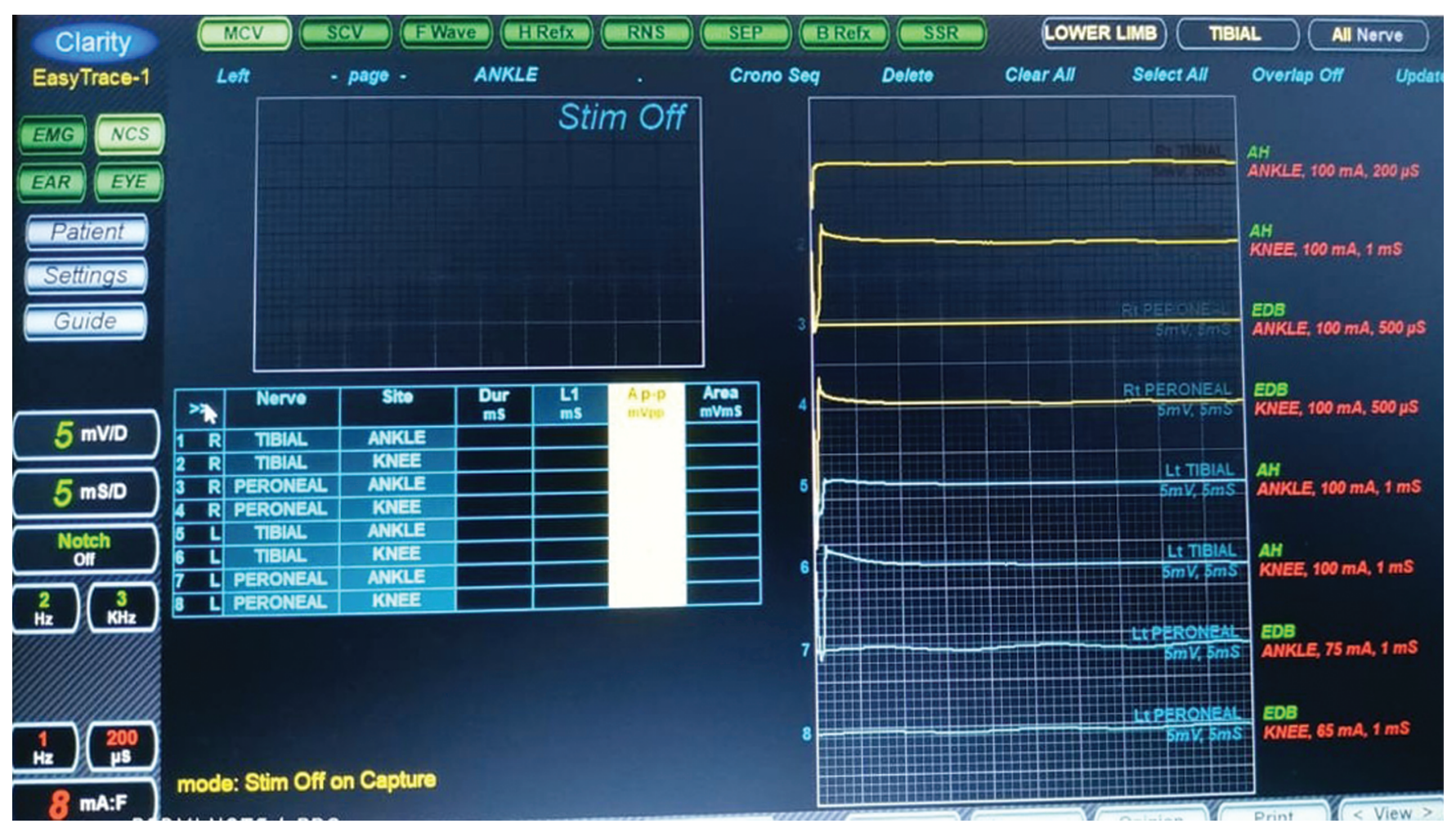

Fig. 1: Nerve conduction study (NCV) of lower limb

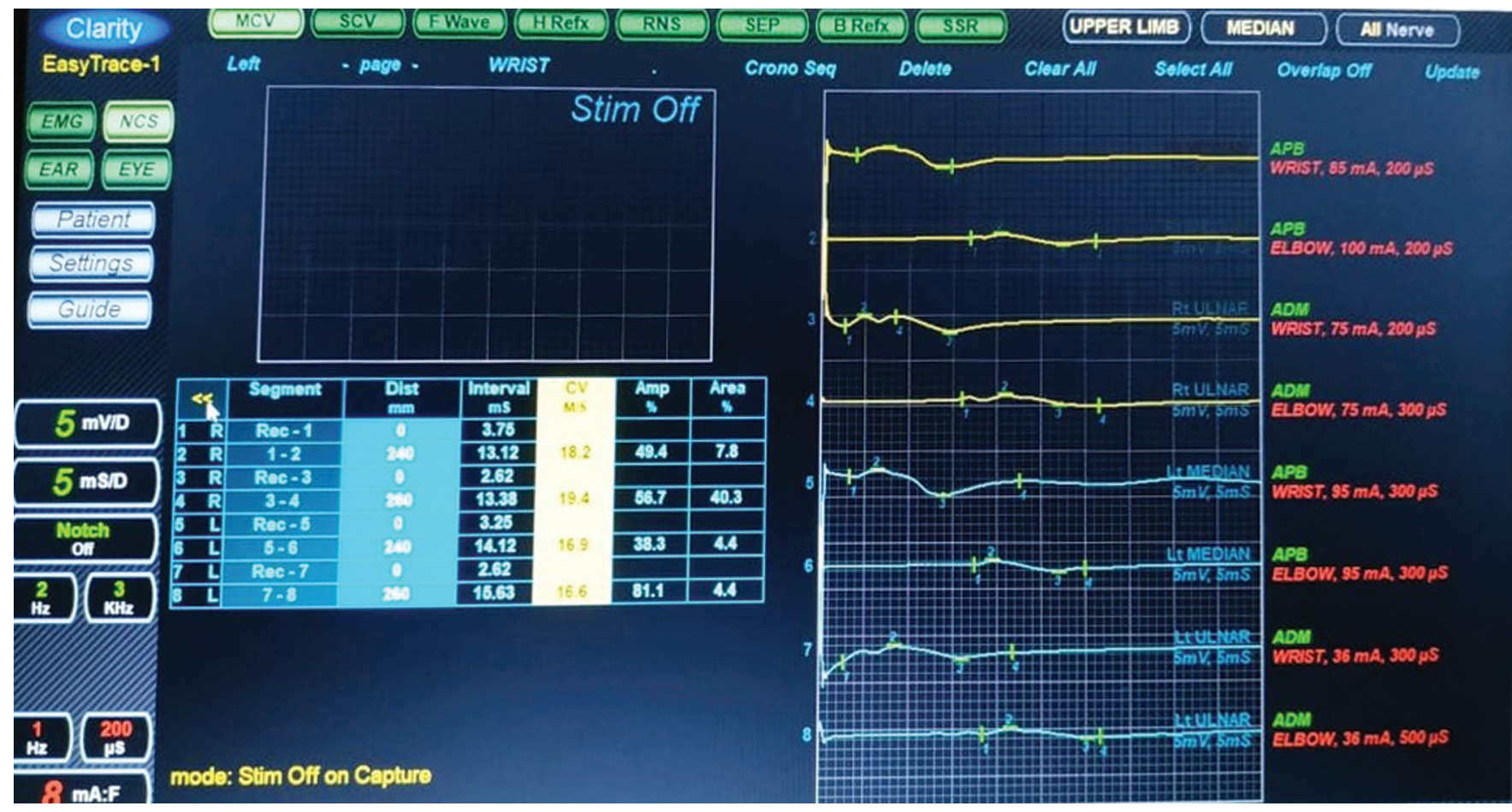

Fig. 2: Nerve conduction study (NCV) of upper limb

possible association in COVID-19 and a decision was made to start on immunoglobulin therapy.

On admission, his high-resolution computed tomography (HRCT) thorax (Fig. 5) revealed bilateral ground-glass opacities and consolidations. He was thrombocytopenic and lymphocytopenic on admission with a neutrophil-lymphocyte ratio of $90: 8$. In the meantime, his nasopharyngeal and oropharyngeal swab test came out to be positive for COVID-19. He was supported with lung-protective ventilation and other supportive treatment. 


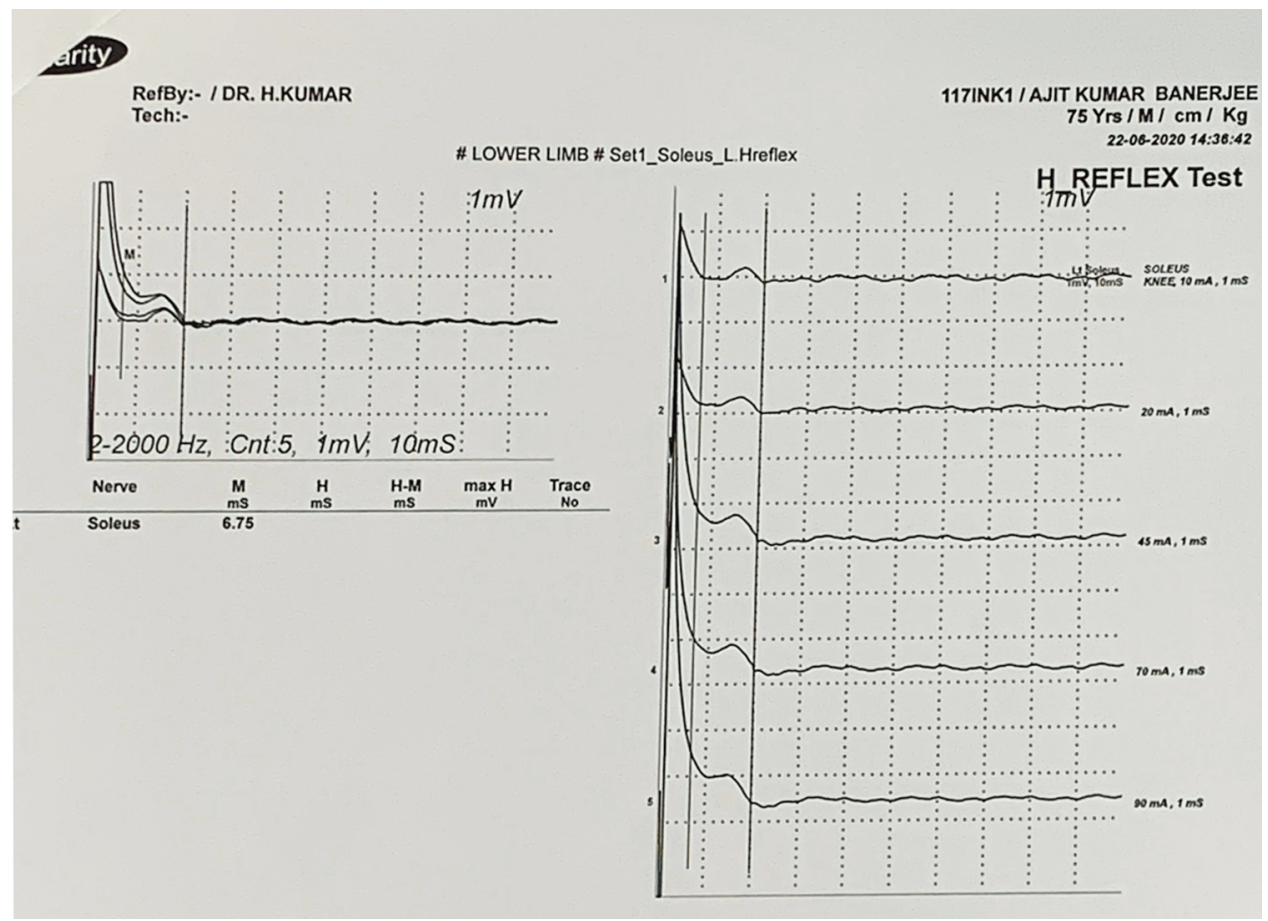

Fig. 3: Lower limb soleus H reflex

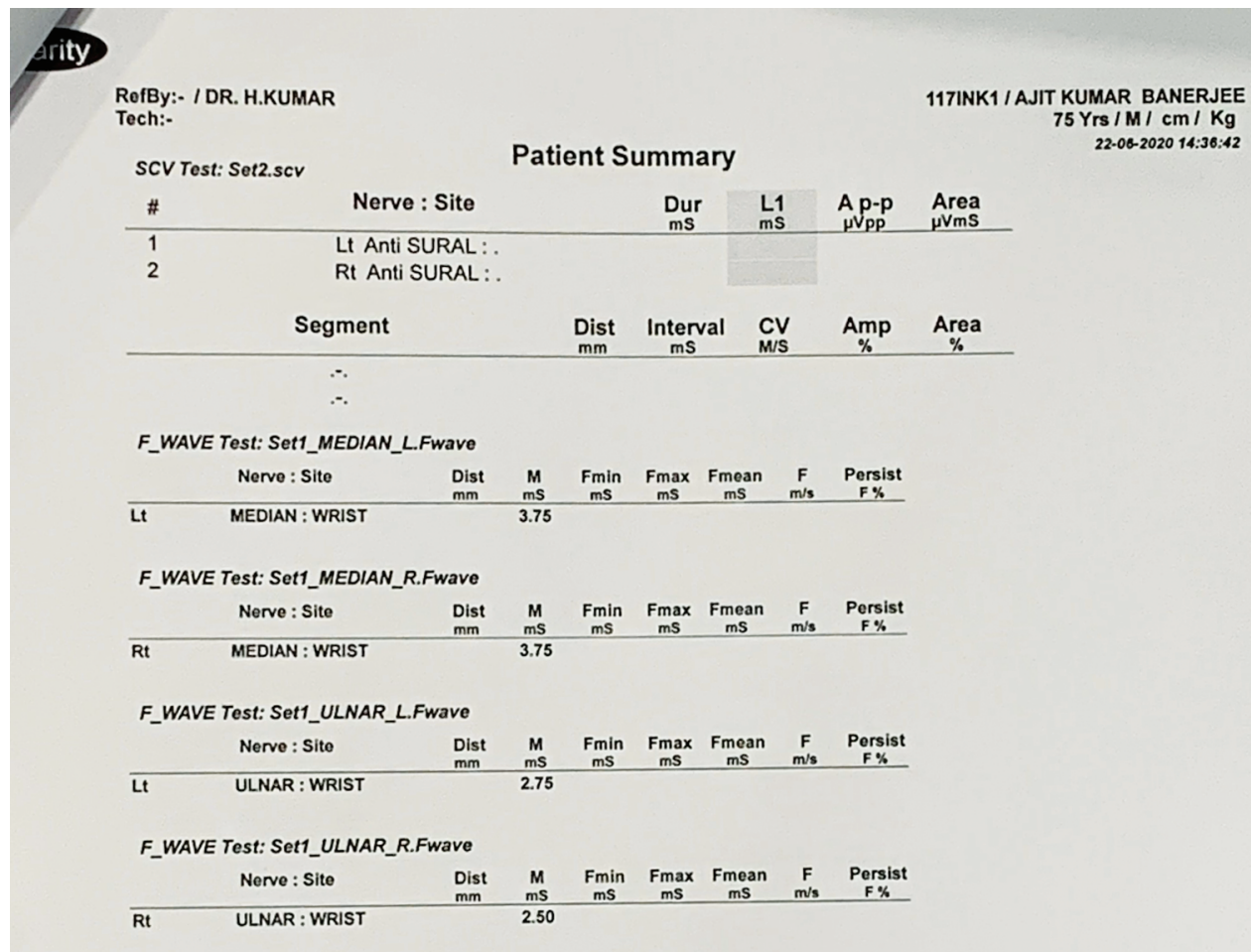

Fig. 4: Upper limb F wave

He was started on IVIg at a dose of $2 \mathrm{~g} / \mathrm{kg}$ of body weight divided over 5 days. In the meantime, his respiratory status worsened to moderate acute respiratory distress syndrome (ARDS) as per the Berlin definition of ARDS. He was supported with culturebased antibiotics, sedated for lung-protective ventilation. Further blood reports also revealed coagulopathy with D-dimer of $1.5 \mu \mathrm{g} /$ $\mathrm{mL}$ and increased serum ferritin of $971 \mathrm{ng} / \mathrm{mL}$. He was continued on pharmacological thromboprophylaxis. His respiratory status further worsened to severe ARDS in the second week of illness. His repeat HRCT scan (Fig. 6) on the 8th day of admission showed an increase in ground-glass opacities and consolidations bilaterally. Fortunately, his respiratory support requirement started decreasing from the 10th day of admission. He was shifted out of isolation after two consecutive negative COVID-19 PCR results. Gradually, 


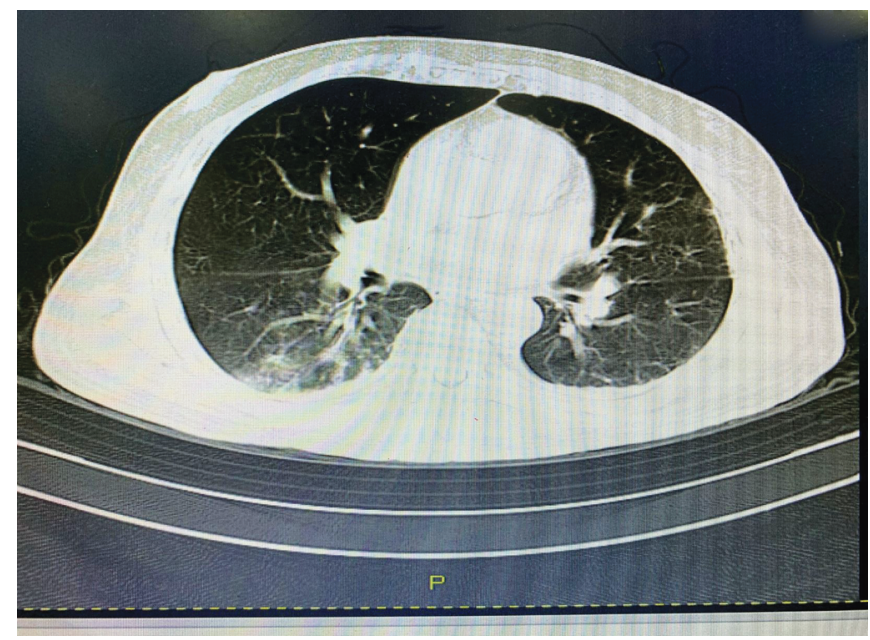

Fig. 5: High-resolution computed tomography (HRCT) thorax on admission

his respiratory status improved further, his ventilator supports were weaned down, and he was extubated on the 17th day of illness. Subsequently, he was discharged from the hospital 24th day of illness with no residual muscle weakness.

\section{Discussion}

Intravenous immunoglobulin, which is produced from mixed plasma of healthy people, is rich in antibodies and viral immunoglobulin $\mathrm{G}$ (lgG). It competitively binds the Fcy receptor to prevent antibodydependent enhancement triggered by virus-antibody immune complexes. ${ }^{3}$ Neutralizing antibodies prevent SARS-CoV-2 spike protein from attaching to the ACE2 receptor, inhibiting viral entry into the cell. ${ }^{4}$ Intravenous immunoglobulin can influence the process of lymphocyte differentiation and maturation, alter the normal immune response of white blood cells, inhibit the production of inflammatory factors, and thus decrease the inflammatory injury experienced by patients. Intravenous immunoglobulin has been clinically used as an adjunctive drug in the treatment of severe pneumonia caused by influenza but there are controversies about its therapeutic effect on COVID-19 pneumonia. ${ }^{5}$ A retrospective study from Wuhan has reported a statistically significant reduction of 28-day mortality, shorter ICU stay, and hospital stay in the IVIg group in COVID-19 pneumonia. Intravenous immunoglobulin has been used successfully in COVID-19-related GBS also. ${ }^{6}$

Previous case reports have reported a time lag from viral prodrome to GBS but our patient was asymptomatic at presentation. ${ }^{7}$ Although IVIg has been used in a few case reports along with other antiviral, steroids, or other postulated therapies in COVID-19 pneumonia or GBS, but in our case, IVIg was used as the sole therapy for immunomodulation. As per our knowledge concerned, only five cases of mixed motor and sensory axonal variant of GBS associated with SARS-CoV-2 have been reported to date. ${ }^{2,8} \mathrm{Administration}$ of IVIg allowed a rapid neurological recovery, reversal of thrombocytopenia, and improvement of coagulopathy and multisystem inflammation (MSI) in this case. He was discharged on the 24th day of admission with MRC grade 5/5 power in all four limbs and clinical recovery of lung function. While the use of hyperimmune globulin requires a tedious job of collection from convalescent patients with verified and adequate titers, the use of IVIg could be an easier option to modulate the immune storm and

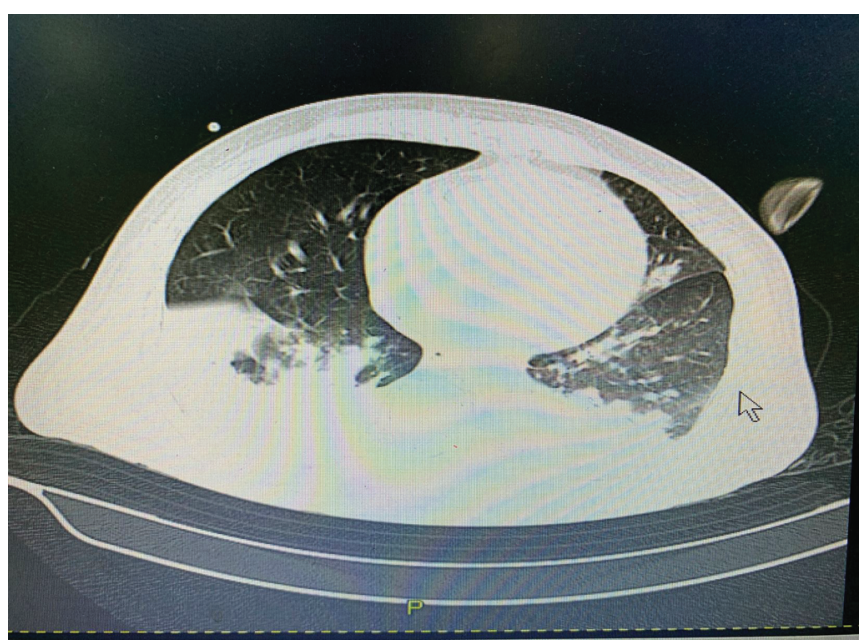

Fig. 6: High-resolution computed tomography (HRCT) thorax second week

faster recovery. Clear demonstration of therapeutic benefit will require further well-controlled studies.

\section{Conclusion}

Neutralizing antibodies in IVIg prevent SARS-CoV-2 virus entry into the cell and limit propagation of antibody-dependent enhancement and MSI in COVID-19. While we wait for a unified decision on the treatment in this pandemic, IVIg may be useful to stop MSI and cytokine storm.

\section{Clinical Significance}

Intravenous immunoglobulin, rich in antibodies can prevent viral entry into the cell; it can inhibit the production of inflammatory factors and decrease the inflammatory injury, MSI in SARS-CoV-2. While the use of hyperimmune immunoglobulin from convalescent patients is a complicated procedure.

\section{References}

1. Zhao $H$, Shen $D$, Zhou H, Liu J, Chen S. Guillain-Barré syndrome associated with SARS-CoV-2 infection: causality or coincidence? Lancet Neurol 2020;19(5):383-384. DOI: 10.1016/S1474-4422(20)301095.

2. Román GC, Spencer PS, Reis J, Buguet A, Faris MEA, Katrak SM, et al. The neurology of COVID-19 revisited: a proposal from the environmental neurology specialty group of the world federation of neurology to implement international neurological registries. J Neurolog Sci 2020;414:116884. DOI: 10.1016/j.jns.2020.116884.

3. Cao W, Liu X, Bai T, Fan H, Hong K, Song H, et al. High-dose intravenous immunoglobulin as a therapeutic option for deteriorating patients with coronavirus diseases 2019. Open Forum Infect Dis 2020;7(3):ofaa102. DOI: 10.1093/ofid/ofaa102. Link: (https://academic. oup.com/ofid/article-abstract/7/3/ofaa102/5810740).

4. Nguyen AA, Habiballah SB, Platt CD, Geha RS, Chou JS, McDonald DR. Immunogobulins in the treatment of COVID-19 infection: proceed with caution! clinical immunology. 2020;216:108459. DOI: 10.1016/j. clim.2020.108459.

5. Lanza M, Polistina GE, Imitazione P, Annunziata A, Di Spirito V, Novella $C$, et al. Successful intravenous immunoglobulin in severe COVID19 pneumonia. ID Cases 2020;21:e00794. DOI: 10.1016/j.idcr.2020. e00794.

6. Xie Y, Cao S, Dong H, Li Q, Chen E, Zhang W, et al. Effect of regular immunoglobulin therapy on prognosis of severe pneumonia in 
patients with COVID-19. J Infect 2020;81(2):318-356. DOI: 10.1016/j. jinf.2020.03.044Link: (https://www.ncbi.nlm.nih.gov/pmc/articles/ PMC7151471).

7. Rodríguez $Y$, Novelli L, Rojas $M$, De Santis $M$, Acosta-Ampudia $Y$, Monsalve DM, et al. Autoinflammatory and autoimmune conditions at the crossroad of COVID-19. J Autoimmun 2020;114:102506. DOI: 10.1016/j.jaut.2020.102506.

8. Ghannam M, Alshaer Q, Al-Chalabi M, Zakarna L, Robertson J, Manousakis G. Neurological involvement of coronavirus disease 2019: a systemic review. J Neurol 2020:1-19. DOI: 10.1007/s00415-020-09990-2. 